\title{
The influence of school size, principal characteristics and school management practices on educational performance: An efficiency analysis of Italian students attending middle schools
}

Citation for published version (APA):

Masci, C., De Witte, K., \& Agasisti, T. (2018). The influence of school size, principal characteristics and school management practices on educational performance: An efficiency analysis of Italian students attending middle schools. Socio-Economic Planning Sciences, 61, 52-69.

https://doi.org/10.1016/j.seps.2016.09.009

Document status and date:

Published: 01/03/2018

DOI:

10.1016/j.seps.2016.09.009

Document Version:

Publisher's PDF, also known as Version of record

Document license:

Taverne

Please check the document version of this publication:

- A submitted manuscript is the version of the article upon submission and before peer-review. There can be important differences between the submitted version and the official published version of record. People interested in the research are advised to contact the author for the final version of the publication, or visit the DOI to the publisher's website.

- The final author version and the galley proof are versions of the publication after peer review.

- The final published version features the final layout of the paper including the volume, issue and page numbers.

Link to publication

\footnotetext{
General rights rights.

- You may freely distribute the URL identifying the publication in the public portal. please follow below link for the End User Agreement:

www.umlib.nl/taverne-license

Take down policy

If you believe that this document breaches copyright please contact us at:

repository@maastrichtuniversity.nl

providing details and we will investigate your claim.
}

Copyright and moral rights for the publications made accessible in the public portal are retained by the authors and/or other copyright owners and it is a condition of accessing publications that users recognise and abide by the legal requirements associated with these

- Users may download and print one copy of any publication from the public portal for the purpose of private study or research.

- You may not further distribute the material or use it for any profit-making activity or commercial gain

If the publication is distributed under the terms of Article 25fa of the Dutch Copyright Act, indicated by the "Taverne" license above,

Download date: 26 Apr. 2023 


\title{
The influence of school size, principal characteristics and school management practices on educational performance: An efficiency analysis of Italian students attending middle schools
}

\author{
Chiara Masci ${ }^{a,}{ }^{*}$, Kristof De Witte ${ }^{\mathrm{b}, \mathrm{c}}$, Tommaso Agasisti ${ }^{\mathrm{d}}$ \\ ${ }^{a}$ MOX-Modelling and Scientific Computing, Department of Mathematics, Politecnico di Milano, Via Bonardi 9, Milano, Italy \\ ${ }^{\mathrm{b}}$ Katholieke Universiteit Leuven (KULeuven), Faculty of Business and Economics, Naamsestraat 69, 3000, Leuven, Belgium

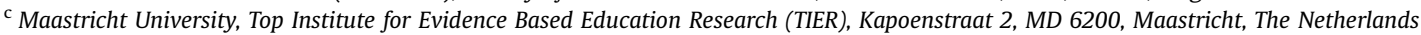 \\ d DIG - Department of Management, Economics and Industrial Engineering, Politecnico di Milano, Via Lambruschini 4/b, Milano, Italy
}

\section{A R T I C L E I N F O}

\section{Article history:}

Received 17 March 2016

Received in revised form

20 July 2016

Accepted 28 September 2016

Available online 1 October 2016

\section{JEL-code:}

I21

C14

\section{Keywords:}

Pupils achievement

Schools efficiency

Management practices

Principal characteristics

\begin{abstract}
A B S T R A C T
The aim of the paper is to identify which among the aspects that relate to the composition of the student body, school (district) size, management practices and the school principals' own characteristics are associated with the performance of Italian students at grade 8, measured through standardised test scores in reading and mathematics. The analysis makes use of a student-level efficiency model, and several school level variables are included as explanators for efficiency scores. The results show that, especially for reading, the most influential variables relate to the composition of the student body, while the students' performance in mathematics is partly correlated with the management practices adopted by the school principal/head teacher. Schools and schooling can only explain a minor part of the variance in achievement scores, however, and the characteristics of the students themselves play the most significant role.
\end{abstract}

() 2016 Elsevier Ltd. All rights reserved.

\section{Introduction}

Empirical analyses of disparity in the quality of education across and within schools is receiving increasing attention (see Refs. $[28,33]$. While there is ample evidence that the quality of schools differs, in terms of value-added, there is more uncertainty about the relevant stakeholders that can help to improve the quality of education. A substantial research effort has been directed towards gaining a better understanding of the potential role that schools play in improving students' learning outcomes.

In many countries, the management practices used by school principals are receiving considerable attention, since, over the last decades and with the introduction of new regulations, schools and

\footnotetext{
* Corresponding author.

E-mail addresses: chiara.masci@mail.polimi.it (C. Masci), Kristof.DeWitte@ kuleuven.be (K. De Witte), tommaso.agasisti@polimi.it (T. Agasisti).
}

principals/head teachers have become more autonomous in a number of fields, including having discretion over their own educational programmes, organising their own activities and introducing innovative teaching methods and initiatives. The resulting heterogeneity in management practices can potentially affect the differences between schools in terms of learning outcomes.

This paper is inserted into the literature that investigates the role that school features have in influencing test scores, in general, and management practices, in particular. In so doing, we follow previous studies where school efficiency is analysed, this being defined as the ability to transform inputs (resources) into outputs (test scores). Scores for European countries are estimated in many articles. However, to our best knowledge, there is no evidence concerning the influence of management practices on school efficiency, or whether management practices are correlated with school performance in general. The key purpose of this paper is to identify which aspects relating to schools, principals 
and school boards are to be acted upon through policies, initiatives and management practices to drive student efficiency. By "students' efficiency" we mean neither direct student performance at school, nor school efficiency, but an index representing the pupils' improvement during junior secondary school (as explained later, measured through improvements over time from test scores at grade 6 to those at grade 8 ). We deal explicitly with the following research question: Which are the school level variables that are statistically associated with the efficiency scores computed at student level?

We will focus on the Italian education system, where there is limited evidence concerning the efficiency of Italian schools (see for example $[1,2,4]$. The literature on Italian schools has explained the school effect primarily through school body composition and school size, since other kinds of information were not available. This limitation corroborates the importance and originality of our dataset: for the first time, we can access information about managerial practices and characteristics of school principals. This allows us to gain a more complete view of the aspects typical of Italian schools. The methodology used to collect this kind of data is also new, since for the first time the National Institute for the Evaluation of the Education System [36] has asked school principals directly through questionnaires - for their point of view about their role, their duties, the performance of their school in different fields and so on. This means that we have (direct and indirect) information regarding all four main groups of school level variables mentioned above.

Beyond the dataset, the innovation of this work is in applying Data Envelopment Analysis (DEA) to compute the efficiency scores of Italian students, considering them as an index of the goodness/weakness of the students' learning. To the best of our knowledge, this is the first study that applies DEA at student level within the Italian context, since most studies use schools as the unit of analysis [23]. In a second step, that of analysing the impact of given variables on the efficiency scores, we look for aspects relating to the management of schools and/or school body composition that are associated with the efficiency of students. We, therefore, contribute to the literature on school management in two ways, by:

(i) Defining the efficiency of students and linking this with management practices, school size and school level characteristics. By applying an innovative dataset and a new method of collecting information through questionnaires sent to school principals, we have precise information on the various activities carried out by the principals;

(ii) Building consistent composite indicators for variables relating to the principals' management practices: we indicate how to summarise information into composite indicators, in an efficient way, in order to create several synthetic indexes relating to the schools' management practices.

To anticipate our main results, we will show that the students' scores for reading and mathematics are certainly influenced by different aspects that are connected to their school. Students' reading achievement is influenced strongly by the composition of the school body, the pupils' peers and the context in which they live. Scores in mathematics also depend on management practices. We will, additionally, confirm that there are striking differences in student learning across macro-areas: students in the South of Italy perform, on average, worse than their counterparts in the North (a result that is consistent with [5]).

It is worth taking into account the fact that this is not the first time that this kind of administrative data has been studied in Italy. $[44,45]$; apply multi-level linear models to analyse how the students' achievements depend on the characteristics of schools, classes and the students themselves. Our work is in stark contrast with these two previous works, for several reasons. First of all, the research question is different: in the previous two studies, the aim was principally to identify the associations between the characteristics of students and students' achievement, and with the effect of attending different schools and classes. Our aim, instead, is to analyse the associations between the numerous features belonging to schools and the students' efficiency. Later, the methodology will differ radically: while the two previous works were based on multi-level linear modelling, in this work, we have applied Data Envelopment Analysis. Lastly, respect to the previous two works, in this analysis, we have introduced a series of new variables collected by [36] that concern the management practices of schools and school principals and which are of major interest in this case.

The paper is organised as follow: in Section 2, we present a review of the relevant literature on the argument; in Section 3, we introduce the dataset and the methodology; Section 4 shows the results and in Section 5, we formulate some conclusive remarks.

\section{Literature review}

In order to obtain an overview of the most important variables associated with student achievements, we have summarised, in Fig. 1, the variables that are identified as influential in the literature, indicating the relationships between them. Student attainment is influenced by three main aspects: (i) the students' features, such as gender, nationality, socio-economic status, attitude towards study, etc.; (ii) the context in which students live, such as the features of their city, district, friends, etc.; (iii) school level characteristics. Regarding the latter point, based upon the literature, there are four main "groups" of variables at school level likely to affect educational performance:

- School body composition and size, such as the percentage of disadvantaged students, average socio-economic status of students, number of students/classes.

- Soft aspects concerning the school, such as school atmosphere and the relationships between teachers, students and parents.

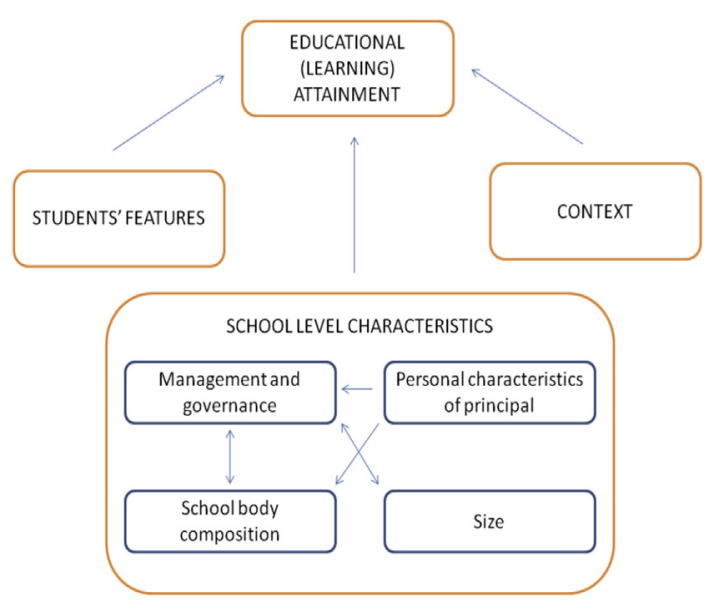

Fig. 1. Aspects that influence learning attainments: (i) students' features, such as gender, nationality, socio-economical status, attitude to study, etc.; (ii) the context in which students live, such as the characteristics of the city, the district, friends, etc.; (iii) school level characteristics, that are management and governance, personal characteristics of principal, size and school body composition (percentages of disadvantaged students, average socio-economical status,etc.). 
- Personal characteristics of school principal, such as gender, age, years of experience and level of education.

- Management practices of school principal, such as their role and duties, their approach to problems and the teachers' responsibilities.

In this paper, we focus on the school level characteristics. In addition to being associated with the students' achievements, these also influence each other. As we will see in the following subsections, the personal characteristics of the principal (such as gender, age and education) may condition his/her style of management and strategy and also the composition of the school body (i.e. by how classes are formed). Management and school body composition influence each other, since the way in which the school body is composed leads to the need for certain management practices and, vice-versa, certain management practices may determine the kind of students who want to attend a given school. The size of the school may ultimately be relevant in the choice of certain management practices, and these, in turn, may be dependent on the school size. The correlation between these variables is, therefore, extremely complex and many aspects should be taken into account at different levels. Given the complexity of these relationships, we are aware that endogeneity is in action here; this means that, in our study, we can identify crucial statistical correlations that cannot be interpreted as causal in any straightforward way.

\subsection{Style of management and composition of school board}

An important variable in influencing student performance is the school's set of management practices [32]. Such practices deal with a number of aspects, from the way the school principal governs the school; considers his/her role; interacts with students and teachers; manages the networks (with other principals or with the school board, for example); influences the academic programme; composes classes; to how they identify the targets and try to reach them; take decisions and so on. The connection between management practices of schools and their efficiency and performance has been explored empirically in many studies. In their pioneering work [31], analyse how the principal management styles effect school improvement and they identify three main styles: Initiators, who have clear ideas on how good schools/schooling and teaching should be and implement actions to achieve their target; Responders, who are compliant principals and want everyone to take part in the decision-making process; and Managers, who are in the middle (they act responsibly towards people, but they also initiate improvement actions). The authors find that Initiators appear to be the most effective in terms of quality and quantity of new programmes implemented [60] analysed the policy-making capacity of Dutch schools and they identified three clusters: in the first, management is dominant, in the second, teachers are dominant and in the third, management and teachers work together. They prove that it is possible to distinguish between types of schools on the basis of their policy-making capacities, concluding that schools where teachers are dominant are most active in implementing instructional and administrative policies [40] provides a review of the literature published over the past two decades concerning the role and effectiveness of school boards in the USA, specifically with respect to how the school boards influence the students' academic achievement. School board experts have identified several important factors: appropriate overarching concerns, which include a focus on the students' academic achievement and attention to policy, not administration; good relationship with the superintendent, between board members, with other local agencies, and with the public and the state; effective performance in the areas of policy-making, leadership and budgeting; and adequate evaluation and training. According to this review, good policies generally contain the following elements: reflection of the board's vision for the school system, coherence with other policies, specification of goals and objectives, definition of roles and responsibilities, flexibility in terms of enacting upon policies, specification of outcomes used to measure success, and compliance with state and federal requirements. [46]; collected information on 700 school districts in Texas by emailing a questionnaire by to school principals, who were asked to indicate, on a six-points scale, the level of interaction between the superintendents and school board members, local business leaders, other school superintendents, state legislators and the Texas Education Agency. Using regression models, they showed that greater network management is positively associated with better student performance (measured as a percentage of students passing tests). [43]; on analysing case studies from 24 schools in the USA, showed that there are two types of leadership, instructional (where the principal is seen as the primary source of educational expertise) and transformational (where the principal concentrates on problemfinding, problem-solving and collaboration). According to the authors, in schools with integrated leadership, that is schools combining both types of leadership, student performance is better. [19]; in a study on data from the British Columbia (Canada), used semi-parametric regression and OLS to assert that school principals can affect student performances, but only when considering their cumulative effect, since principals need time to implement changes in a school. [12]; collected information from 1,800 schools educating 15 year-olds in eight countries, asking school principals for interviews concerning four areas of management (operations, monitoring, target setting and people management). They used linear models to find that a good average management score is related with better student performance, stating that the principals' accountability and strategy are at the basis of good governance in schools. Regarding the debate on public and private schools [28], used a multi-level approach to analyse the [51] scores for 22 countries, finding that students in both private government-dependent and private independent schools have, on average, better reading scores than students at state/public schools [12] on the other hand, found that autonomous (private) schools performance better than state/public schools, and these, in turn, perform better than purely private schools. The difference between these three types of schools is reflected in different degrees of the principal's accountability and strategy. Analyses based on PISA (Programme for International Student Assessment) data, after observing the results of the test in different countries, show that autonomy and accountability go together: greater autonomy in decisions relating to curricula, assessments and the allocation of resources tends to be associated with better student performance, but only when schools operate within a culture of accountability, otherwise, autonomy without accountability makes for worse performance [33]. Regarding the Italian context, [26]; having defined five areas of management where school principals are evaluated in a scale from 1 (worst) to 5 (best), discovered that Italian school principals are, on average, less able than principals in other countries. This is due to their lack of management skills rather than any lack of autonomy: giving autonomy to schools without improving the principals' management skills can be highly 
detrimental. Competition, independence and accountability are at the basis of efficient school management.

All these studies prove that school management practice and the strategies of the schools' principals can create differences across schools. Having said this, the literature also presents cases where it is not possible to find a connection between management practices and student performance [48] assert that school-based management (SBM) has gained popularity as a method for local participating schools to improve their schools, but there is little empirical evidence supporting a link between SBM and improved school performance [54] show that school-based management can be effective, but only when the conditions associated with highinvolvement organisations - namely, decentralisation of power, knowledge and skills, information and rewards - are in place. [56]; used data relating to Portugal to classify schools depending on the students' performance and to collect information about management practices; their evidence is, however, inconclusive with regards to the relationship between performance management practices and the type of schools.

In general terms, therefore, the literature points at an underlying relationship between management and student results and, in this paper, our aim is to explore this correlation within the current Italian educational system. In our empirical analysis, however, we have not been able to obtain information about the composition of the governing bodies and their functions, so we concentrated our attention mainly on the principals' specific management practices.

\subsection{Principal's characteristics and education}

The variables that may be relevant for management practices at schools are also those that describe the principals' personal characteristics, such as gender, age, experience and level of education [38]. Studies have been carried out on the relationship between a school's performance, leadership and the personal characteristics of the school's principal [29] used meta-analytic methods to review 50 studies that compared the leadership styles of principals at public schools, finding that women scored higher than men for task-oriented measures and in adopting a more democratic and/or participative style.

[18]; on analysing data for New York City, found a positive relationship between the principal's experience and school performance, particularly for test scores in mathematics. [14]; from a study on data about Texas schools, showed that more years of experience for a school principal are correlated with higher school achievement. In particular, comparing schools with lowest average initial achievement and schools with highest average initial achievement, there are roughly $40 \%$ more principals in their first year at a school in the former than in the latter. In addition, there are roughly $50 \%$ more principals who have been at their current school for at least six years in the highest achieving schools. [26]; in Italy, and Bloom et al. [12] found that female principals are associated with higher management scores and better performance than males principals [26] found, that the female principals make up one third of the total number of principals, which means that they are more likely to have been positively selected, implying that women who succeed in becoming principals are, on average, more able than men. In both cases, the studies involve building a management ranking on the basis of interviews with school principals and then analysing the correlation between principals' characteristics and management level. When considering the principals' age, in both studies, the authors find that younger principals are better than older ones. With regards to their educational level, they show that principals with a humanistic or scientific education achieve higher management scores than principals with technical background.

[25] studied the administrative records in North Carolina (USA) to explore whether the school principals' education has a direct effect on student performance. They found that having an advanced academic degree brings increased value-added in reading, while having a non-competitive doctorate degree increases value-added in mathematics [3] analysed [36] data to explore the relationship between the principal's characteristics (in particular, experience as school principal, gender, age and degree subject) and both management practices and student achievement. They found no pattern as to the connection with the students achievement. Looking at management practices, they found that women state that they make greater use of management practices than men; the age of the school principal is positively related to the use of management practices and, finally, there is a negative correlation between the number of years as school principal and the use of selected practices, but the direction of the connection reverses when considering tenure at a specific school.

\subsection{Compositional effects: characteristics of students (at school level) and size}

Further literature confirms that the variables describing the composition of school body also play an important role in school performance $[50,27,43,14]$; for example, show that schools with a high percentage of disadvantaged students (immigrant students, low socio-economic status ...) are connected with low school leadership and bad performance. [11]; analysed the relationship between the students' family income and their achievement. They analysed longitudinal data from the UK, exploring the expansion of higher education (HE) across different years (1981, 1993 and 1999) and its influence on richer and poorer students. They argue that educational inequality has moved through time and the results show that HE expansion has disproportionately benefited children from middle income families. Despite the fact that many more children from higher income backgrounds were in HE before the recent expansion of the system, the expansion had the effect of widening the gap between richer and poorer children [50] analysed PISA data for 2003 in Australia to examine the relationship between a school's average ESCS (socio-economic status) and student outcomes. They found that increases in the average ESCS for a schools are associated with different increases to the students' academic achievement, and that this relationship is similar for all students regardless of their individual ESCS. Among previous uses of data similar to those used in this paper, [44,45]; analysed data from Italy (grade 6) through hierarchical models, showing that the composition of the school body, specifically the percentage of girls, immigrants and late/early-enrollers and average ESCS, is influential within the school effect and weighs differently across different geographical macro-areas.

Lastly, numerous works in literature show that the size of classes, schools, school boards and districts may have an impact on the students' performance. Regarding class effect [46], assert that, in Texas, class size is negatively associated with good student performance [39] carried out a comprehensive analysis of the literature on school size, concluding that the literature suggests that smaller classes have a positive effect on student achievement. School district size is another factor that may be influential. We know from recent review studies and meta-analyses is that both 
Table 1

Groups of school-level variables that influence students' results - a selected literature review.

\begin{tabular}{|c|c|c|}
\hline Style of management and composition of school board & Correlation with students' achievements & Correlation with school leadership \\
\hline Instructional and transformational leaderships & Positive: Ref. [43]: & Positive: Refs. [26,60] \\
\hline 4 types of management (operation,monitoring target setting,people) & Positive:Ref. [12] & Positive: Ref. [26] \\
\hline Principal accountability and strategy & Positive: Refs. [12,19] & Positive: Ref. [31] \\
\hline Good efficiency of school board & Positive: Ref. [40] & \\
\hline Network Management & Positive: Refs. [46,40] & \\
\hline Private independent school & Positive: Ref. [28] & $\begin{array}{l}\text { Negative: Refs. [12,44,45] } \\
\text { Positive: Ref. [28] }\end{array}$ \\
\hline Private government-dependent & Positive: Ref. [28] & \\
\hline Autogovernate schools & & Positive: Refs. [12,51] \\
\hline Management & Uncorrelated: Refs. [48,56] & \\
\hline Principal's characteristics and education & Correlation with school leadership & Correlation with students' achievements \\
\hline Being older/experience & $\begin{array}{l}\text { Negative: Ref. [26] } \\
\text { Positive: Ref. [3] }\end{array}$ & $\begin{array}{l}\text { Positive: Ref. [18] } \\
\text { Ref. [14] } \\
\text { Uncorrelated: Ref. [3] }\end{array}$ \\
\hline Being female & Positive: Refs. [3,12,26,29] & \\
\hline Have a high educational level & Positive: Ref. [26] & Positive: Ref. [25] \\
\hline \multicolumn{3}{|l|}{ Students' characteristics (at school level) and size } \\
\hline Percentage of disadvantage students & Negative: Refs. $[14,43]$ & Negative: Ref. [27] \\
\hline \multirow[t]{2}{*}{ School district size } & Negative: Ref. [27] & \\
\hline & $\begin{array}{l}\text { Optimal middle size: Refs. [6,21,35,41,49]: } \\
\text { Uncorrelated: Ref. [53] }\end{array}$ & \\
\hline Class size & Negative: Refs. $[39,46]$ & \\
\hline Family income & Positive: Ref. [11] & \\
\hline
\end{tabular}

"very small" and "very large" school sizes are less conducive to the quality of education $[6,21,41,49,27]$ analysed 5,525 schools representing 755 districts through linear models. One in six schools in California are in districts with more than 40,000 students. One in twelve schools are in the Los Angeles Unified School District, where nearly 600,000 students were tested in 1999. He showed that students in larger districts have lower scores. [35]; on analysing 60,000 pupils in public schools in Denmark, found, that, in terms of optimal school performance, the best district size is between 15,000 and 30,000 inhabitants [53] analysed data on the 99 largest American districts for 1999 and 2000, exploring, through linear models, the impact of district size on four variables: total expenditure per pupil, expenditure on support services per pupil, quality of education within the district and production efficiency in the district. While he found that district size has a positive influence on the expenditure per pupil and a negative influence on the production efficiency of the district, he did not find any connection between district size and quality of education, measured as the average test scores of the students in the district [42] carried out a quantitative and qualitative analysis of the research-based evidence of school size effects within primary and secondary education. They observed that the numerous existing studies show different results and opposite school size effects. Having analysed 126 studies covering the effect of the school size on the students' achievements, they found that, in $62 \%$ of cases, it appears to be nonsignificant, in $18 \%$ of cases, it has a negative effect and in $9 \%$ of cases, it has a positive effect. Table 1 gives a global overview of these results.

Table 1 shows a global overview of these results.

\section{Data and methods}

\subsection{The dataset}

In Italy, [36], a public agency founded in 2007 and run under the supervision of the Ministry of Education, assesses students' skills in reading and mathematics at different stages. Standardised tests are taken at the end of the second and fifth years of primary school (when pupils are 7 and 10 year of age, respectively), at the end of the first and third year of lower secondary school (at 11 and 13) and at the end of the second year of upper secondary school (at 15 years of age). Pupils are asked to answer multiple choice and open-ended questions to test their ability in reading and mathematics. This is a way to test the pupils' knowledge and reasoning against what they should have learned up to that point in their schooling. Students are also asked to fill in a questionnaire about themselves, their family, their parents' educational level and their socio-economic status. As a final point, [36] requires a selected (and nationally representative) sample of pupils to answer a new questionnaire about their principals, in terms of their characteristics and operations. It is worth noting that this analysis is carried out on a sample of schools in the Italian educational system (National Sample, NS) and not on all of them.

The dataset of interest contains information, collected by [36], on 6572 Italian 13-year old students in the third year of junior secondary school in 2013/2014, from 462 schools. Initially, the sample selected by [36] to be included in our analysis contained 28,145 students from 1414 schools. Having removed the pupils with missing or incomplete data at levels that we consider to be essential, we obtained a smaller dataset. This subsample is still representative of the entire set of Italian schools (see Appendix 1). The information was collected by setting tests in reading and mathematics to students and asking both students and school principals to complete a questionnaire. The following information is available at pupil level: gender, immigrant status (Italian or immigrant), whether the student is an early-enroller (i.e. was first enrolled at five years-old, the norm being to start the school at six years old ${ }^{1}$ ), or if the student is late-enroller (this is the case when the student must repeat a year, or if he/she is admitted to school a year later to catch up, being an immigrant). From previous studies,

\footnotetext{
1 The school-year cut-off date in Italy is 31 December but sometimes, when children are born at the early months of the calendar year, parents can choose to let them start school one year early.
} 
we know that being a late enrolled student is usually associated with lower average scores $[4,44,45]$. With regards to the variables, $51.7 \%$ of our sample are girls, $8.7 \%$ are immigrant children, $1.2 \%$ of the pupils are early-enrollers and $4.2 \%$ are late-enrollers. [36] collects information about the socio-economic status of the students, based on elaborating an indicator (known as ESCS-Economic and Social Cultural Status), which is similar to that proposed in the OECD-PISA framework. This indicator considers (i) parents' occupation and educational qualifications, and (ii) whether they own certain items at home (for instance, the number of books). Once measured, this indicator was standardised for a mean of zero and variance of one. The minimum and maximum observed values in the [36] dataset are -3.05 and 2.67, respectively. In general, pupils with an ESCS greater or equal to 2 are highly advantaged socially and culturally (their family has a high socio-economic background). The data includes the [36] scores for mathematics and reading tests taken in the first year of junior secondary school (CMS1 and CRS1 respectively, ranging between 0 and 100 , where the mean and standard deviation are 48.6 and 16.8 for mathematics and 66.3 and 14.1 for reading, respectively); this allows us to include a valueadded factor to the students' educational results. Regarding geographical location, we have included two dummies for schools located in Central and Southern Italy (compared to the North, which is the reference variable) and the district in which the school is located. This is because some previous literature pointed towards showing that students at schools in Northern Italy tend to obtain higher achievement scores than their counterparts in other regions, all else being equal $[5,15]$. Of the students in our sample, $52 \%$ are at a school in northern Italy, $18 \%$ in the Centre and 30\% in the South. The outputs MS and RS (scores for mathematics and reading, respectively, in the standardised tests set by [36]) are expressed as 'cheating-corrected' scores (CMS3 and CRS3). ${ }^{2}$ These variables take values between 0 and 100, and the mean and standard deviation are, respectively, 59.7 and 16.4 for mathematics and 64.0 and 16.5 for reading. The main variables of interest for this paper are those relating to school level factors. Regarding the composition of the school body, school-level averages for several individual characteristics include: class-average ESCS, the proportion of immigrant, late/early-enrolled pupils and the number of girls. We also have information about the size of the school/class: number of students in the class and number of school facilities/buildings (in our sample, the class coincides with the school, since we only collect information from a single class in each school). A dummy is included to distinguish private schools from public schools (8.2\% are private schools). With regards to management practices and dynamics of the schools, school principals are asked to complete a questionnaire with about 30 questions (and numerous sub-questions) that covers a number of different aspects, including personal features, such as gender, age, education, experience, etc.; information about what they feel that their role entails, their duties and management strategies; the relationships between students, parents and teachers; and the structures and infrastructures of the school. This very innovative dataset has allowed us to explore new aspects relating to the schools and correlate them to the students' performance. Table 2 gives the variables at school level that are used in the analysis, together with three additional composite indicators that we have created, presented in section 3.2.2. The original questionnaire submitted to the school principals, with all the variables and their descriptive statistics, is shown in Appendix 3.

One of the three composite indicators concerns management

\footnotetext{
${ }^{2}$ INVALSI in fact estimates the propensity for cheating as a percentage, based on the variability of intra-class percentage of correct answers, types of wrong answers, etc.; the resulting estimates are used to "deflate" the raw scores in the test.
}

Table 2

School-level variables of the database used in the analysis, with their descriptive statistics.

\begin{tabular}{lllll}
\hline Explanatory variables & & & & \\
\hline Variable Name & Mean & sd & Min & Max \\
\hline Mean ESCS & 0.26 & 0.54 & -1.76 & 2.67 \\
Female percentage & 50.1 & 10.8 & 11.11 & 80.95 \\
Immigrant percentage & 10.5 & 11.1 & 0 & 89.47 \\
Early-enrolled student percent & 1.2 & 4.1 & 0 & 40 \\
Late-enrolled student percent & 9.0 & 8.5 & 0 & 43.75 \\
Number of classes & 14.8 & 4.0 & 6 & 32 \\
Number of school complexes & 5.37 & 2.81 & 1 & 10 \\
Private & $8.2 \%$ & 0.27 & 0 & 1 \\
Center & $19.9 \%$ & 0.40 & 0 & 1 \\
South & $29.7 \%$ & 0.45 & 0 & 1 \\
Principal features: & & & & \\
Gender(Female $=1$, Male $=0)$ & $70 \%$ & 0.46 & 0 & 1 \\
Age & 55.1 & 7.49 & 27 & 72 \\
Master or similar after degree & $22 \%$ & 0.40 & 0 & 1 \\
Scientific education(yes $=1)$ & $14.6 \%$ & 0.33 & 0 & 1 \\
Year of experience & 9.23 & 7.79 & 0 & 44 \\
Year of experience in the & 5.08 & 5.18 & 0 & 33 \\
actual school & & & & \\
Experience in an other district & $25.3 \%$ & 0.43 & 0 & 1 \\
Experience with INVALSI & $51.3 \%$ & 0.50 & 0 & 1 \\
Satisfaction of principal about & 7.24 & 1.81 & 1 & 10 \\
his/her autonomy & & & & \\
He/She asks information out of the & 0.96 & 0.20 & 0 & 1 \\
school about complex problems & & & & \\
\hline
\end{tabular}

practices in schools. We have also promoted a discussion on the main different subcategories in this area that are used as potential explanations for different levels of student achievement. Following the classification proposed by Refs. [12,26] (which is coherent with the one proposed by the World Management Survey), we have clustered together all the information about management practices and the school principals' strategy (given in the 11-th and 12-th questions in the questionnaire) into five areas:

- Operation: Standardisation of instructional planning processes, personalisation of instruction and learning, data-driven planning and pupils transferring between schools, adopting educational best practices;

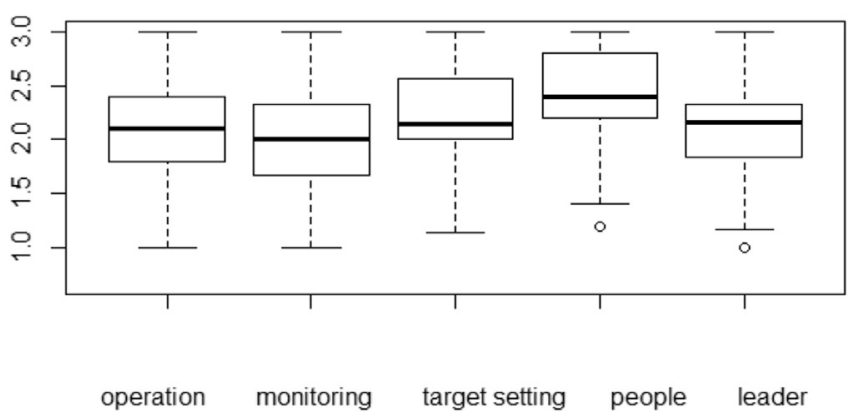

Fig. 2. Box-plots of the 5 areas of management: operation (process standardization, use of best practices and school curriculum decisions); monitoring (supervision of school activities and performances and management of anomalies in school processes); target setting (ability of setting clear goals for the school and managing resources in order to reach them); people (ability to guarantee professional development of teachers and to retain best teachers in the school); leader (leadership skills and the ability to clearly define roles and responsibilities in the school) 
- Monitoring: Continuous improvement, performance tracking, review and dialogue; consequence management;

- Target setting: Target balance, target interconnection, time horizon of targets, target stretch, clarity and comparability of targets;

- People management: Rewarding high performers, fixing poor performers, promoting high performers, managing talent;

- Leader: Principal's strategy, role, duties and responsibilities.

Fig. 2 contains the box-plots of these five management variables. Each variable ranks between 1 (worst case) and 3 (best case). From the range of the box-plots, we can see that there is variability, meaning that there are differences in the five areas across different schools. In particular, operations and monitoring are seen to be the most variable, while people management is the least variable.

\subsection{The methodology}

The analysis consists of a two-stage procedure. In the first part, we estimate the students' efficiency scores through Data Envelopment Analysis, while the second part consists of a second stage regression in which we relate the efficiency scores to some school level variables using truncated linear regression and the Bootstrap method. Although the literature usually assesses efficiency at school-level, there are examples of student-level efficiency assessments (see, for example, [62]. In this work, we decided to concentrate our analysis at student level. We interpret the efficiency scores as a 'pure efficiency gain' at student level and we leave the analysis of school-level variables as an explanation for efficiency differentials, which are determined over time. In the past, no other studies have followed this approach in studying the efficiency of Italian schools. All the analysis are run using the software R (Ref. [52]).

\subsubsection{First-stage: student level efficiency via DEA}

The main statistical tools used in this analysis are based on Data Envelopment Analysis (DEA), that is, a linear programming tool (and a non-parametric method) for evaluating the relative efficiency of a set of similar entities (e.g. firms, schools), given observations on (possibly multiple) inputs and outputs. DEA was originally developed by Ref. [30] and put into practice by Ref. [17].

Assume that there are data on $N$ inputs and $M$ outputs for each unit $I$. For the i-th unit these are represented by the column vectors $x_{i}$ and $q_{i}$, respectively. The $N x l$ input matrix, $X$, and the $M x l$ output matrix, $Q$ represent the data for all $I$ units. An intuitive way to introduce DEA is via the ratio form. For each unit, we would like to obtain a measure of the ratio of all outputs over all inputs, such as $\frac{u^{\prime} q}{v^{\prime} \chi}$, where $u$ is an $M x l$ vector of output weights and $\mathrm{v}$ is a Nxl vector of input weights. The optimal weights are obtained by solving the mathematical programming problem:

$\max _{u, v}\left(\frac{u^{\prime} q_{i}}{v^{\prime} x_{i}}\right)$

s.t.

$\frac{u^{\prime} q_{i}}{v^{\prime} x_{i}} \leq 1 \quad$ with $\quad i=1, \ldots, I$

$u, v>0$.

This involves finding values for $u$ and $v$, such that the efficiency measure for the i-th unit is maximised, subject to the constraint that all efficiency measures must be less than or equal to 1 . One problem with this particular ratio formulation is that it has an infinite number of solutions. To avoid this, one can impose the constraint $v^{\prime} x_{i}=1$, which provides:

$$
\max _{\mu, \nu}\left(\mu^{\prime} q_{i}\right)
$$

s.t.

$$
v^{\prime} x_{i}=1
$$

$\mu^{\prime} q_{i}-\nu^{\prime} x_{i} \leq 0 \quad$ with $\quad i=1, \ldots, I$

$\mu, \nu \geq 0$

where the change of notation from $\mathrm{u}$ and $\mathrm{v}$ to $\mu$ and $\nu$ is used to stress that this is a different linear programming problem (see Ref. [20]). The DEA follows the assumptions of convexity and free disposability and can assume constant or variable returns to scale (VRS and CRS respectively). Return to scales are considered to be increasing if a proportional increase in all the inputs results in more than a proportional increase in the single output. If $\alpha$ represents the proportional input increase and $\beta$ represents the proportional increase in the single output, increasing returns to scale prevail if $\beta>\alpha$, while decreasing returns to scale prevail if $\beta<\alpha$ (in both cases, we have assumed VRS). On the other hand, if an increase in inputs does result in a proportional change in the outputs, then constant returns to scale (CRS) are assumed [7].

We chose to use DEA in this analysis for several reasons. First, non-parametric methods can handle multiple inputs and outputs in a simple manner, while most stochastic approaches require choosing a single output variable. Second, non-parametric approaches do not require any assumptions about the functional form or specification of the error term, while stochastic methods need these assumptions. In the end, the sources of inefficiency can be analysed and quantified for every evaluated unit. Furthermore, education is a popular area of application for DEA [23]. DEA has some disadvantages too [10]: the results are very sensitive to the selection of inputs and outputs, which means that the correct choice of inputs and outputs is essential to estimate efficiency in the right way. It is not possible to test for the best specification and the number of efficient schools on the borderline tends to increase with the number of inputs and output variables. Therefore, in order to avoid some of these problems, we will later introduce the bootstrap method proposed by Ref. [58].

We start by applying the output-oriented DEA, with variable return to scale assumption [20], in order to estimate the two efficiency scores for students, in reading and mathematics, respectively. We assume variable returns to scale because we suspect that an increase in inputs does not result in a proportional change in the output. We apply two different and independent models, one considering the mathematics scores, estimating the student's efficiency in mathematics, and the other one considering the reading scores, estimating the student's efficiency in reading. Due to the longitudinal nature of the data and other information at student level, we compute the efficiency score of the students, which is not the student's direct performance, but the student's improvement in education during junior secondary school (value-added formulation). In particular, 
Table 3

Variables of the database used in the DEA, with their explanation and descriptive statistics.

\begin{tabular}{|c|c|c|c|c|c|}
\hline Variable name & Explanation & Mean & sd & Min & Max \\
\hline \multicolumn{6}{|l|}{ Input } \\
\hline Gender & Dummy variable that differentiates females $(1)$ from males $(0)$ & $51.7 \%$ & 0.5 & 0 & 1 \\
\hline Immigrant & Dummy variable that differentiates immigrants( 1$)$ from Native Italians $(0)$ & $8.7 \%$ & 0.28 & 0 & 1 \\
\hline ESCS & Socio-economic index & 3.36 & 1.01 & 0 & 5.73 \\
\hline $\begin{array}{l}\text { CMS } 1-1^{\text {st }} \text { year secondary } \mathrm{j} \text {. } \\
\text { school math score }\end{array}$ & $\begin{array}{l}\text { INVALSI score in maths of students attending } \\
\text { the } 1^{\text {st }} \text { year of secondary j. school }\end{array}$ & 48.6 & 16.8 & 5.93 & 97.10 \\
\hline $\begin{array}{l}\text { CRS1-1 }{ }^{\text {st }} \text { year secondary } \mathrm{j} \text {. } \\
\text { school reading score } \\
\text { Output }\end{array}$ & $\begin{array}{l}\text { INVALSI score in reading of students attending } \\
\text { the } 1^{\text {st }} \text { year of secondary j. school }\end{array}$ & 66.3 & 14.1 & 5.16 & 98.57 \\
\hline $\begin{array}{l}\text { CMS3- } 3^{\text {rd }} \text { Math Score } \\
\text { corrected for Cheating }\end{array}$ & $\begin{array}{l}\text { INVALSI score in maths of students attending } \\
\text { the } 3^{\text {rd }} \text { year of secondary j. school }\end{array}$ & 59.7 & 16.4 & 4.51 & 97.93 \\
\hline $\begin{array}{l}\text { CRS3- } 3^{\text {rd }} \text { Reading Score } \\
\text { corrected for Cheating }\end{array}$ & $\begin{array}{l}\text { INVALSI score in reading of students attending } \\
\text { the } 3^{\text {rd }} \text { year of secondary j. school }\end{array}$ & 64.0 & 16.5 & 2.86 & 98.45 \\
\hline
\end{tabular}

we model the efficiency of the educational process at studentlevel, by considering previous scores and personal characteristics as inputs, and the current test scores as output. The inputs of the DEA (at student level) are:

- ESCS (Economic, Social and Cultural Status)

- INVALSI test score [36] score (in reading or mathematics) at the first year of junior secondary school (grade 6)

where the output is:

- INVALSI test score [36] score (in reading or mathematics) at the third year of junior secondary school (grade 8).

Table 3 shows the variables that we have used in the analysis, specifying the inputs and outputs of the DEA model.

As we mentioned before, the correct choice of outputs and inputs is essential in the DEA. Since we want to evaluate the educational improvement of students during junior secondary school, we consider the scores at grade 6 as "starting level" (inputs) and the scores at grade 8 as "product" of the three academic years (outcomes). Furthermore, we introduce ESCS to the inputs, that is, the personal characteristics of students which we consider as a determinant in the students' efficiency. Previous studies on this topic of Italian data point towards significant associations between this variable and the students' achievements.

The Data Envelopment Analysis method is used here to provide some measures of the students' efficiency. These measures allow the students to be ranked according to their apparent performance. The bootstrap method [57,58] is useful to correlate the efficiency scores with a set of school level covariates, and to obtain a robust estimation of the influential variables. Since the observations come from some data-generating processes, the statistical properties of the estimated efficiency measures are essential for them to be interpreted. In the general multi-output multi-input framework, the bootstrap method seems to offer the only means of inferring these properties (i.e. to estimate the bias and variance, and to construct confidence intervals) [58]. The idea behind bootstrapping is simply to simulate the sampling distribution of interest by mimicking the data-generating process (DGP).

The four steps of Bootstrap method are the following (see Ref. [59]:

1) Using the original data, estimate the DEA efficiency score $\theta_{i}$ for all units employing equation (1);
2) Employing truncated maximum likelihood method, estimate $\widehat{\beta}$ and $\widehat{\sigma_{\varepsilon}}$ of the model

$\theta_{i}=z_{i} \beta+\varepsilon_{i} \geq 1$

where $\mathrm{z}$ is a vector of variables assumed to impact on the choice and use of outputs and inputs, $\beta$ is a vector of parameters to be estimated and $\varepsilon$ is a continuous iid random variable, distributed $N\left(0, \sigma_{\varepsilon}^{2}\right)$;

3) For each $\mathrm{i}=1, \ldots, I$ loop the following steps $L$ times to yield a set of bootstrap estimates $B_{i}=\left\{\left(\widehat{\beta}^{*}, \widehat{\sigma}_{\varepsilon}^{*}\right)_{b}\right\}_{b=1}$ :

3.1) for each $\mathrm{i}=1, \ldots, I$ draw $\varepsilon_{i}$ from the $N\left(0, \sigma_{\widehat{\varepsilon}}\right)$

3.2) for each $\mathrm{i}=1, \ldots, I$ compute $\theta_{i}^{*}=z_{i} \widehat{\beta}+\varepsilon_{i}$

3.3) Employing the maximum likelihood method, estimate $\widehat{\beta}^{*}$ and $\widehat{\varepsilon}^{*}$

4) Use the Bootstrap values in $B$ to construct the confidence intervals (and other descriptive statistics) for each element of $\beta$.

A major advantage of bootstrapping is its simplicity. It is a straightforward way to derive robust estimates of standard errors and confidence intervals for complex estimators of complex parameters of the distribution, such as percentile points, proportions, odds ratios and correlation coefficients. Bootstrapping is also an appropriate way to control and check the stability of the results. In any case, we should consider that, although bootstrapping is (under some conditions) asymptotically consistent, it does not provide general finite-sample guarantees.

\subsubsection{Second-stage: school level factors associated with students efficiency}

Before presenting the set of the explanatory variables at school level, we note that the number of variables included in the questionnaire asking about the principal's characteristics and management practices (which are the candidate covariates for this second stage) is very high; it could, therefore, be useful to create some composite indicators in order to collect and join variables related to the same settings. The idea is to identify variables that explain the same aspect from different points of view and enclose their information in a unique indicator. We, therefore, introduce the "benefit of the doubt model" (BoD). This method makes it possible to reduce the space of variables, to delete problems of collinearity in the empirical models and to summarise information concerning the same aspect. This is not a new concept in the educational field: applying composite indicators in the educational context is a rather common technique (see, for example $[37,24]$ ). 
Table 4

Composite indicators: descriptive statistics.

\begin{tabular}{|c|c|c|c|c|c|}
\hline Composite indicators & Mean & Median & sd & Min & Max \\
\hline Ind 1: school climate and human relations & 0.959 & 1 & 0.088 & 0.5 & 1 \\
\hline Ind 2: managerial practices and principal's strategy & 0.859 & 0.833 & 0.108 & 0.5 & 1 \\
\hline Ind 3: structures and resources of the school & 0.937 & 1 & 0.090 & 0.666 & 1 \\
\hline
\end{tabular}

The benefit of the doubt model (BoD), labelled so by Ref. [47]; is basically the DEA but with the difference that we only take a look at the outputs, without explicitly taking the inputs into account. The aim is to construct a composite-score based on a large array of single-dimensional performance indicators $i$, having no a priori precise understanding concerning the exact importance of each of these indicators. Formally, in the DEA setting, all evaluated entities are assumed to have a 'dummy input' equal to one. The main conceptual starting point of BoD estimators (and, thus, from DEA in which they are rooted), is that information on the appropriate weights can be retrieved from the observed data themselves (i.e. letting the data speak for themselves). In this way, BoD weights $w_{c, i}$ are optimal, in the sense that they are chosen in such a way as to maximise the composite-score $B o D_{c}(y)$ :

$\operatorname{BoD}_{c}(y)=\max _{w_{c, i}} \sum_{i=1}^{q} w_{c, i} y_{c, i}$

s.t.

$\sum_{i=1}^{q} w_{c, i} y_{j, i} \leq 1 \quad$ with $j=1, \ldots, c, \ldots n$

$w_{c, i} \geq 0 \quad$ with $i=1, \ldots, q$

The main idea is that the output criteria on which the evaluated unit performs well compared to the other units in the reference set should weigh more heavily than the output criteria on which it performs relatively poorly. Each unit can have a specific set of variables that are more important than others and, consequently, its performance should weigh more heavily on this criterion (i.e. high weighting $w_{c, i}$ ). In other words, for each unit taken separately, BoD looks for the weights that maximised (minimises) the impact of the criteria where the unit performs relative well (poorly) compared to the other units. Hence, BoD-weights $w_{c, i}$ are optimal and yield the maximal composite-score. In our paper, we use the BoD method to build synthetic indicators at school level that can gather together the main characteristics which we consider to be potentially associated with the students' efficiency. The three composite indicators that we create at school level are the following:

1) Ind1: the first indicator is related to the relationships between students, teachers and parents and to the parents' and students' behaviour (school atmosphere and human relations). It is built by considering the information given in a subset of questions: the 14th, 15th, 16th, 18th and 19th 1-4 scale range questions in the questionnaire (see Appendix 3). Schools with a high first indicator are schools where the relationships between students/ teachers/parents are good, parents are present in the children's school life and students behave well at school.

2) Ind2: the second indicator, relating to the management practices and the principals' strategies, contains the information given in the 11th and 12th questions (see Appendix 3) (management practices and principal's strategy). The 29 sub-questions were initially grouped following the classification set by Refs. [12,26] (operations, monitoring, target setting, people management and leader $)^{3}$ and the five new variables were used to create the indicator. High indicators represent schools where the principals interact with students, are responsible, have a good strategy and efficient policy management.

3) Ind3: the third indicator summarises the level of operations for structures, infrastructures and laboratories at the school (structures and resources of the school). It is built from the 22th and 23th questions (see Appendix 3). Schools with a high indicator have functioning structures and laboratories of a quality that is judged as high by the principals themselves.

The aim is to obtain an index of school efficiency for each of these three aspects. The higher the efficiency score (the indicator) the better the school performance in the related area. The three efficiency scores are built using the BoD method, based on the DEA, implemented in R using the benchmarking package [13], assuming constant return to scale (CRS) and solving the linear programming problem (9). They range between 0 (least efficient) and 1 (most efficient).

Table 4 gives some descriptive statistics of the three composite indicators defined above. The median is 1 for the first and the third indicators, which means that more than half of the schools are totally efficient in the related area (indicator $=1$ ), or, at least, the principals consider their school to be totally efficient. The most variable indicator is the one related to management practices: this is the aspect that differs most across schools. When considering these management practices, school principals give very heterogeneous answers, because they have different strategies and roles, and these differences may make the difference between schools in terms of efficiency. In the section that follows, our aim is to investigate this aspect empirically.

\section{Results}

\subsection{Efficiency scores (at student level)}

Histograms, boxplot and several descriptive statistics of efficiency scores are shown in Fig. 3 and Table 5, for both reading and mathematics.

From this analysis, it emerges that the average efficiency score in reading is a bit higher than that of mathematics ( 0.6673 vs 0.6351 ). Looking at the histograms, we can also see that the distribution of the efficiency scores in mathematics is quite symmetric, while that of reading one has a tail in the direction of the lower scores, suggesting that most students are rather efficient, but that there is a substantial portion for whom efficiency is low. In a certain way, the efficiency score of each pupil reflects the efficiency score of the school that she/he attends, since the INVALSI test score [36] score taken in the first year of junior secondary school basically depends on the education that the pupil received at primary school, while

\footnotetext{
${ }^{3}$ The classification of the management practices in the five areas is shown in Appendix 4; see Ref. [3].
} 

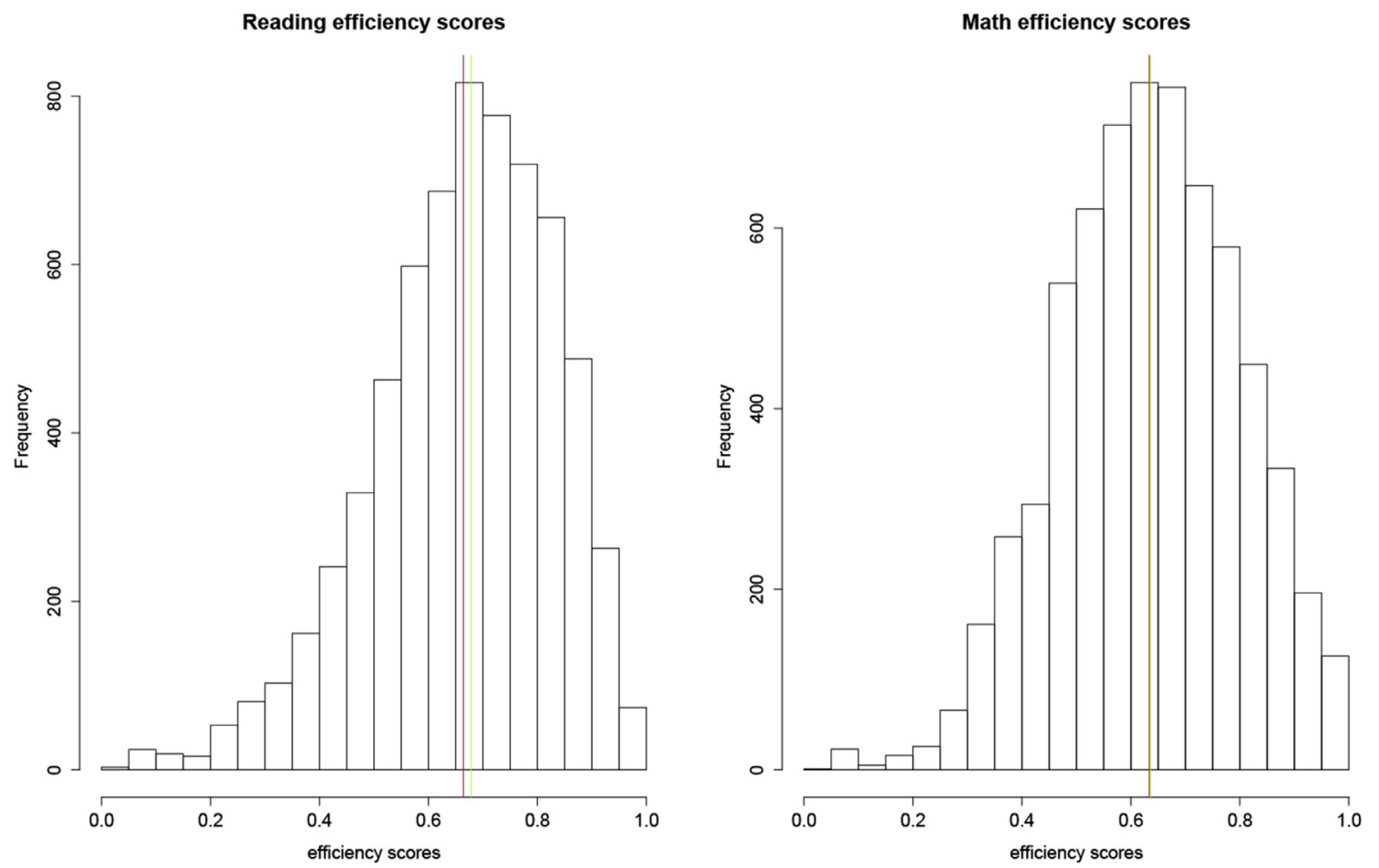

Efficiency scores

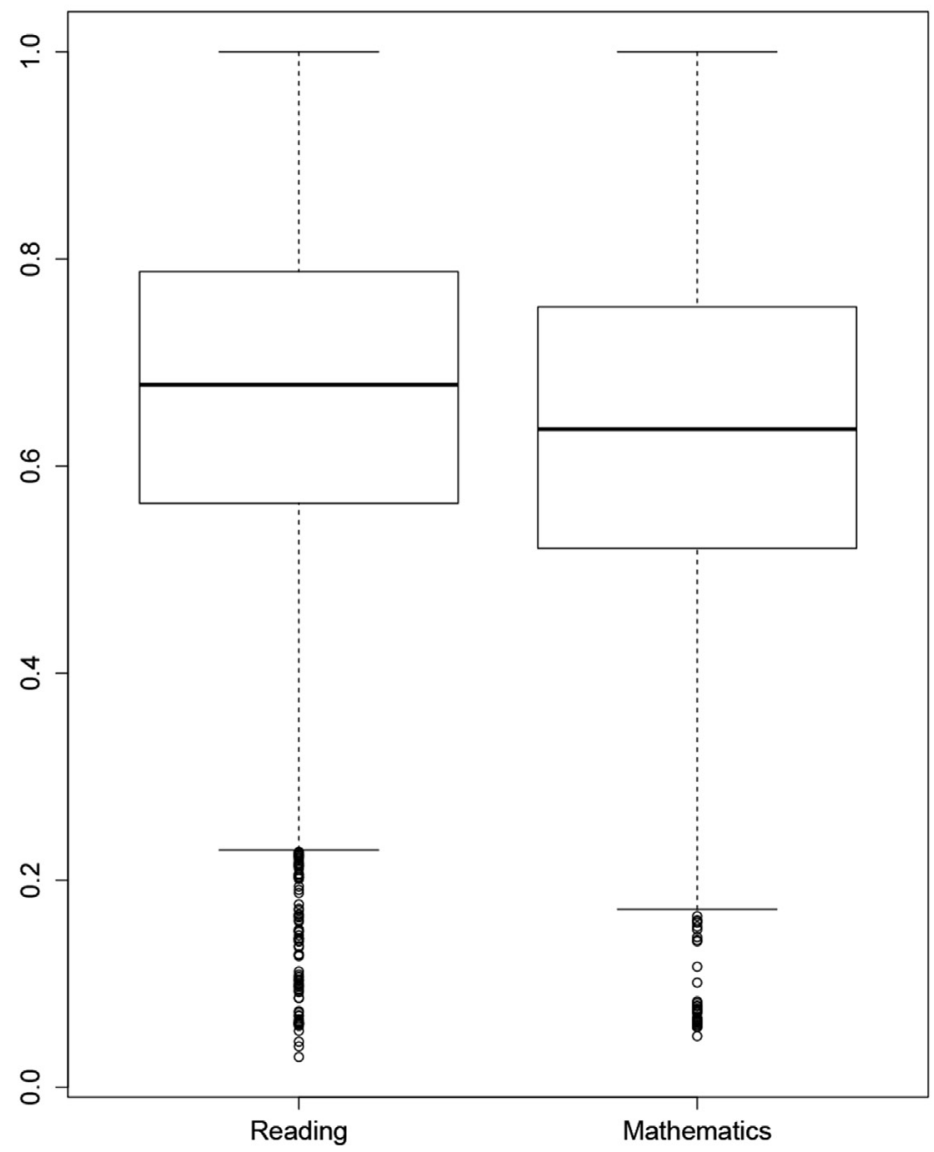

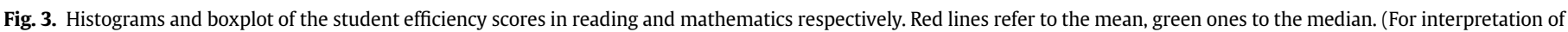
the references to colour in this figure legend, the reader is referred to the web version of this article.) 
Table 5

Efficiency scores (students): descriptive statistics.

\begin{tabular}{llllll}
\hline Efficiency scores & Mean & Median & sd & Min & Max \\
\hline Reading & 0.6643 & 0.6787 & 0.1662 & 0.0292 & 1 \\
Mathematics & 0.6338 & 0.6357 & 0.1645 & 0.0493 & 1 \\
\hline
\end{tabular}

Table 6

Average student efficiency scores in math and reading stratified for characteristics of pupils.

\begin{tabular}{llll}
\hline Student characteristic & Average efficiency & & Average efficiency \\
& Score in math & & Score in reading \\
\hline Females & 0.6213 & 0.6768 \\
Males & 0.6471 & 0.6508 \\
Immigrants & 0.6027 & 0.6162 \\
Native Italians & 0.6367 & 0.6689 \\
Early-enrolled & 0.6088 & 0.6466 \\
Regular & 0.6341 & 0.6645 \\
Late-enrolled & 0.5686 & 0.5731 \\
Regular & 0.6366 & 0.6683 \\
\hline
\end{tabular}

Table 7

School level factors associated with student-level efficiency scores. Notes: ML average estimates of the 2,000 Bootstrap iterations. Asterisk denotes that variables for which more than 1,600 p-values over 2,000 are less than 0.05 .

\begin{tabular}{llll}
\hline Variable & Reading & Mathematics \\
\cline { 2 - 3 } & Coef & & Coef \\
\hline Compositional effect and size:: & & \\
Intercept & $0.632^{*}(0.037)$ & & $0.587^{*}(0.038)$ \\
South & $-0.063^{*}(0.005)$ & & $-0.050^{*}(0.005)$ \\
Center & $-0.013^{*}(0.005)$ & & $-0.024^{*}(0.005)$ \\
Female percentage & $-0.000(0.000)$ & & $0.000(0.000)$ \\
Immigrant percentage & $0.000(0.000)$ & & $-0.000(0.000)$ \\
Late-enrolled percent & $0.001^{*}(0.000)$ & & $-0.001^{*}(0.000)$ \\
Early-enrolled percent & $-0.001^{*}(0.001)$ & & $-0.004(0.001)$ \\
Private & $-0.033^{*}(0.008)$ & & $-0.009(0.009)$ \\
Mean ESCS & $0.033^{*}(0.005)$ & & $0.011(0.005)$ \\
Number of classes & $0.001^{*}(0.000)$ & & $0.001(0.001)$ \\
Number of school complexes & $-0.002^{*}(0.001)$ & $-0.001(0.001)$ \\
\hline
\end{tabular}

the INVALSI test score [36] score taken in the third year of secondary school reflects the impact that the secondary school has on the student ${ }^{4}$. In order to check the robustness of the DEA, Appendix 2 shows an alternative method which does not assume the convexity of the sample.

It can be interesting to examine whether there is a trend in the efficiency scores across different types of students, which can be used to recognise kinds of pupils that perform better than others. We compute the mean of the efficiency scores in mathematics and reading by stratifying for the students' characteristics (see Table 6). In both fields, we observe that the average efficiency score of immigrant students is lower than that of native Italians (0.6042 vs 0.6381 in mathematics and 0.6192 vs 0.6719 in reading) and that the average efficiency scores of both

\footnotetext{
${ }^{4}$ Since the DEA contains the monotonicity assumptions of the inputs, we have not included the variables 'gender' and 'immigrant' in the inputs. Both these two variables are, in any case, considered as influential in the students' outcomes. We, therefore, repeated the DEA to include these two variables in the inputs, in order to see whether we obtained different estimates for the students' efficiency. For both reading and mathematics, we obtained very similar estimates: both the Pearson's correlation tests provide a p-value of less than $2.2 e-16$ and a coefficient of correlation greater than 0.999. These results confirm that we do have the statistical evidence to say that the DEA efficiency scores estimated with and without the variables 'gender' and 'immigrant' are the same.
}

early and late-enrolled students are on average lower than those of the regularly enrolled students $(0.6100$ and 0.5718 vs 0.6381 for the early and late enrolled students, respectively, vs the regularly enrolled student in mathematics, and 0.6493 and 0.5773 vs 0.6715 in reading). Regarding gender, behaviour varies between mathematics and reading. Boys perform on average better than girls in mathematics (0.6496 vs 0.6216$)$ whilst girls perform on average better than boys in reading ( 0.6769 vs $0.6570)$. In order to test the difference between the means of the distributions we are comparing, we have computed the Wilcoxon test on each, obtaining very low p-values (less than 0.01 in all cases). This means that, in all cases, we have sufficient evidence to say that the means of the groups are different.

\subsection{School-level variables associated with efficiency scores}

The next step is to identify which aspects of school body composition, management practices, principal's characteristics, relationships between students/parents/teachers and structures/ infrastructures of schools are driving these efficiency scores. For the reasons presented in Section 3, we have used the one-step bootstrap method to obtain a more robust estimation of the coefficients. We employed truncated linear models in which the answer variables are the students' efficiency scores, and the variables at school level are the covariates. It is worth taking into account the fact that we have no information on students moving between schools. Therefore, we considered the characteristics of the schools attended by the students at grade 8 , assuming that the students stay in the same school for the entire three years (from grade 6 to grade 8 ). The R packages used to compute this analysis are boot [16] and truncreg [22]).

Tables 7 and 8 show the results of the bootstrap estimation, comparing the coefficients of reading and mathematics. We computed 2000 bootstrap iterations, showing here the mean, the standard deviation and the significance of the 2000 coefficients for each variable. To compute this significance, we have taken into account the number of times a variable is significant ( $p$-value less than 0.05 ) in the 2000 regression models and we then consider as significant those that are significant in more than 1600 models out of the 2000 .

Geographical area plays an important role for scores in both reading and mathematics. Attending a school in the Centre and even more so in the South of Italy is negatively associated with the students' efficiency (coefficients respectively -0.013 and -0.063 for reading and -0.024 and -0.050 for mathematics). This is not a new result, as previous studies show that students in the North of Italy have, on average, better results than students in the Centre and especially in the South, all else being equal $[5,44,45]$.

When considering efficiency in reading, the most relevant variables are those describing the composition of the school body (i.e. the students' average socio-economic status at school level). The percentage of late-enrolled students weighs positively (coefficient 0.001), while that for early-enrolled students weighs negatively (coefficient -0.001 ). Attending private schools has a negative relationship with student learning (coefficient -0.033), suggesting that private school students obtain lower test scores than students at public schools, once ESCS is taken into account. This result is in line with most of the previous literature on private schools in Italy (see, for example [3,44,45]. Schools with a high ESCS show higher student efficiency, so that the average ESCS is positively associated with student learning (coefficient 0.032). This is a result confirmed also in the previous literature, since the ESCS is directly proportional to family income, which weighs positively [11], and is inversely proportional to the 
Table 8

School level factors associated with student-level efficiency scores. Notes: ML average estimates of the 2,000 Bootstrap iterations. Asterisk denotes that variables for which more than 1,600 p-values over 2,000 are less than 0.05 .

\begin{tabular}{lll}
\hline Variable & Reading \\
\cline { 2 - 2 } & Coef \\
\hline Principal's features:: & $-0.002(0.004)$ \\
Gender(Female $=1)$ & $0.000(0.000)$ \\
Age & $-0.014^{*}(0.005)$ \\
Master after degree & $0.008(0.005)$ \\
Scientific education & $0.001(0.000)$ \\
Year of experience & $-0.000(0.001)$ \\
Year of experience in the actual school & $0.008(0.004)$ \\
Experience in an other district & $-0.012^{*}(0.004)$ \\
Experience INVALSI & $-0.003^{*}(0.001)$ \\
Satisfaction of principal about his/her autonomy & $0.006(0.010)$ \\
He/She asks information out of school about complex problems & $-0.001(0.005)$ \\
School management and resources:: & $0.013^{*}(0.005)$ \\
Indic1: school climate and human relations & $-0.009(0.024)$ \\
Indic2: managerial practices and principal's strategy & $-0.000(0.001)$ \\
Indic3: structures and resources of the school & $-0.009(0.005)$ \\
\hline
\end{tabular}

percentage of disadvantaged students, which weighs negatively $[43,14]$. Looking at class size and school size, the more students in the class, the better the students' efficiency, while the higher the number of school facilities, the worse the students' efficiency. The relation between school/class size and school performance is one of the least clear and most highly discussed in the literature, with many papers showing negative connections, others showing positive ones and others still showing that they are not correlated (see the survey proposed by Ref. [42].

Looking at the school principals' characteristics, there are few relevant variables. Having a principal with an education in science is associated with higher student learning in mathematics (coefficient 0.013 ), while it does not statistically matter for reading, where, instead, principals with higher educational level (a Master or a post-degree specialisation) are linked to lower student efficiency (coefficient -0.014 ). In both reading and mathematics, principals who have had experience with [36] are associated with lower student efficiency. Lastly, regarding the three composite indicators, the only one that is significant is the index of management practices (indicator 2), which weighs positively (coefficient 0.071 ) on the students' learning in mathematics, suggesting that schools with a good management style and expert principals can facilitate student learning in this field. This is coherent with the vast literature that connects good management practices with good student achievement. Other characteristics belonging to principals, such as gender, age and years' experience is not significant in either field, contrarily to the findings of [26] and [12].

It is interesting to observe that the socio-economic composition of the school body weighs on the students' learning in reading more than in mathematics. Indeed, as we could expect, the pupils' reading skills are mainly influenced by their socio-economic background and their living environment and by the peers with whom they associate and talk to most. On the other hand, the students' learning in mathematics depends less on these aspects, but could, instead, derive from the technical characteristics of teaching and the management practices.

Overall, our findings suggest that there are several characteristics at school level that may influence student efficiency. In any case, we should consider that there are various levels of information and aspects that play a role in this field. The pupils' learning is the result of a combination of school characteristics, school principals, teachers' ability, family background and, the most important one, pupils' skills. Among others [34], tries to explain what drives the variance in education. According to the author, $50 \%$ of students' education depends on the students themselves, $30 \%$ depends on their teachers, $10 \%$ on their family background and their peers and the final $10 \%$ on the school principal. The results provided in this paper must be also interpreted under the awareness that the greater part of the variance in achievement scores lies in differences between students rather than between schools.

\section{Concluding remarks}

In this paper, we have analysed the achievement in reading and mathematics on a sample of 6572 Italian students attending grade 8 in 2013/2014. The information at student and school levels was obtained by [36] and we have built a novel specific dataset primarily used for the purposes of our study. We have explored the extent to which some students gain better learning outcomes than others, computing, for each of them, an efficiency score, that takes account of the INVALSI test score [36] scores obtained in the first and third years of junior secondary school and other personal characteristics (gender and ESCS). Contrarily to the approach in which student outcomes are represented directly by the INVALSI test score [36] scores, here we have focused on student efficiency scores, which are a measure of the ratio between student learning and the resources employed to achieve this level of education. In this way, we have not considered the students' skills but their improvement during junior secondary school.

The first important consideration regards the geographical areas: from the results, it emerges that attending a school in the Centre and especially in the South of Italy is statistically associated with a lower student learning. This topic is highly topical and policy-relevant in Italy, where the differences across the geographical areas are of great interest to researchers. In the educational field, many previous studies underline the same feature (see, for example $[2,4,5,44,45]$.

The main aim of this work is to find out how characteristics at school level, such as the composition of the school body, school size, human relationships within the school, structures and infrastructures, management practices and personal characteristics of principal influence, these scores. A strong point of this paper is that we consider simultaneously four areas of information at school level: (I) school body composition and size (such as mean ESCS, number of students, percentage of disadvantaged students ...) (II) soft aspects of the school (such as school atmosphere, human relationships ...) (III) personal characteristics of school principals and 
(IV) management practices. This allows us to compare these four areas and identify the most influential that should be acted on to improve school efficiency.

The results show that there are some differences between the factors that affect reading and mathematics test scores. The efficiency scores in reading are mainly influenced by the socioeconomic composition of the student population, such as percentage of early/late-enrolled students and average ESCS. This means that the students' reading skills are influenced more by the environment in which the pupils live and by their peers. Regarding the scientific area, these variables are not significant, while the index of management practices is relevant: learning in mathematics depends, in part, on the quality of the management practices that the school principal adopts to improve teaching efficiency. It was additionally seen that the personal characteristics of the principal can be influential, including the kind of education they had received or their experience with INVALSI test score [36]. These results, together with those on management practices, suggest that choice of the school principals is critical, because some of their aspects may weigh on the school performance of the students in their care. In particular, management duties, educational programmes, innovations in teaching methods and initiatives, as stated by the school principals, can make the difference.

However, we should note that the three composite indicators (school atmosphere, management practices and resources), which we created from the questionnaire sent to school principals, do not show such wide variation, meaning that the school principals tend to give homogeneous answers and, more especially, positive ones. The indicator that results to be most heterogeneous concerns management practices, which is the area in which principals have different points of view and apply different strategies. Therefore, school management can have a role in affecting the educational results of students, suggesting that efficient management can lead to higher student learning. These results, however, may depend on the way in which we collect the information about management. The questionnaire submitted to the principals contains questions that may be subjective and there is the risk that their answers do not actually reflect the true management style of the school. For this reason, one of our future tasks is to expand the analysis of the school questionnaire, by trying to collect information on this area in different ways, such as through face-to-face interviews or by telephone, or by formulating new questions, and so follow other different approaches that may be more effective in clearly defining the contribution of different principals.
Politecnico di Milano. The authors are grateful to INVALSI for having provided the original dataset, to Patrizia Falzetti for her statistical assistance in building our specific database and to John Ruggiero, Lory Taylor and Cinzia Daraio for their comments during the workshop 'Efficiency in Education' in Leuven. We thank Francesca Ieva, Anna Maria Paganoni and Mara Soncin for their comments during the preparation of this work. Chiara thanks KU Leuven, Faculty of Economics and Business, for their hospitality during the research period.

\section{Appendix 1}

\section{Representativeness of the sub-sample}

As anticipated before, the analyses are made on a reduced dataset. We mainly discard all the statistical units for which some essential variables, such as the $1^{\text {st }}$ year of junior secondary school math and reading scores, the ESCS or variables at questionnaire level, were missing. It is worth to evaluate the representativeness of this sub-sample with respect to the entire population from a statistical point of view. Since the sample size at pupils level is extremely high, is quite impossible to find a non-significant difference in statistics summarizing the student's level features. Moreover the CRS/CMS- $1^{\text {st }}$ scores and the questionnaire's variables are data transmitted to INVALSI at the school level. For these reasons we check the representativeness of the sub-sample studying the distributions of some school level variables. For the continuous ones we perform a non parametric comparison test (Wilcoxon test) to detect possible differences in the stochastic distributions generating data. For the dichotomic ones we perform a comparison test between proportions.

In particular, there is no strong statistical evidence for difference with respect to mean ESCS ( $\mathrm{p}$-value $=0.1045$ ), females percentage $(p$-value $=0.9381)$, immigrants percentage $(p$-value $=0.0708)$, early-enrolled students percentage $(p-v a l u e=0.2925)$ and lateenrolled students percentage $(p$-value $=0.7323$ ). Focusing on the geographic distribution, the proportion of schools in the three macro-areas are not statistically different ( $p$-values: 0.3134 for the North, 0.7016 for the Center and 0.1533 for the South). Instead, there is a high statistical evidence that private schools are underrepresented in the reduced dataset (p-value less than 2.2e-16). Overall, the reduced dataset used in this paper is substantially representative of the original population, with the only exception of the proportion of private and public schools. In the following table we show some descriptive statistics and comparison tests of the variables of interest.

Table 9

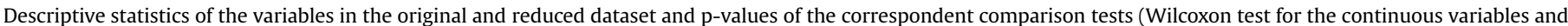
test between proportions for the dichotomic ones).

\begin{tabular}{|c|c|c|c|c|c|}
\hline \multirow[t]{2}{*}{ Variable } & \multicolumn{2}{|c|}{ Original dataset } & \multicolumn{2}{|c|}{ Reduced datadet } & \multirow{2}{*}{$\begin{array}{l}\text { Comparison test } \\
\text { p-value }\end{array}$} \\
\hline & Mean & sd & Mean & sd & \\
\hline Mean ESCS & 0.215 & 0.566 & 0.269 & 0.546 & 0.1045 \\
\hline Female perc & 50.065 & 12.106 & 50.178 & 10.875 & 0.9381 \\
\hline Immigrants perc & 9.991 & 12.145 & 10.525 & 11.178 & 0.0708 \\
\hline Late-enrolled perc & 9.348 & 9.001 & 9.084 & 8.586 & 0.7323 \\
\hline Early-enrolled perc & 1.453 & 4.526 & 1.284 & 4.106 & 0.2925 \\
\hline North & 0.454 & - & 0.484 & - & 0.3134 \\
\hline Center & 0.182 & - & 0.192 & - & 0.7016 \\
\hline South & 0.363 & - & 0.322 & - & 0.1533 \\
\hline Private & 0.437 & - & 0.082 & - & $2.2 e-16$ \\
\hline
\end{tabular}

\section{Acknowledgments}

This work is conducted within FARB - Public Management Research: Health and Education Systems Assessment, funded by

\section{Appendix 2}

The DEA is not the only method to estimate efficiency scores in this kind of data. A similar method is the Free Disposal Hull (FDH). The 
main difference between these two methods is that, respect to the $\mathrm{FDH}$, the DEA has the further assumption that there is convexity in the sample used in the analysis. Since we do not know whether our data are convex or no, we implement the FDH in order to compare the efficiency scores estimated by these two methods and to check the robustness of the DEA. For both reading and mathematics, the Pearson's correlation test provides a p-values less than $2.2 e-16$ and the coefficients of correlation between the efficiency scores estimated by
DEA and FDH are respectively 0.858 for reading and 0.877 for mathematics. Moreover, from Fig. 4 we can see that there is a linear relation between the DEA and FDH estimates. Both the test of correlation and the plots show that we have evidence to say that there is not statistically significant difference between the efficiency scores estimated by DEA and FDH. We can then conclude that the DEA is quite robust in the estimate of the efficiency scores of these data.

\section{FDH vs DEA estimates in reading}

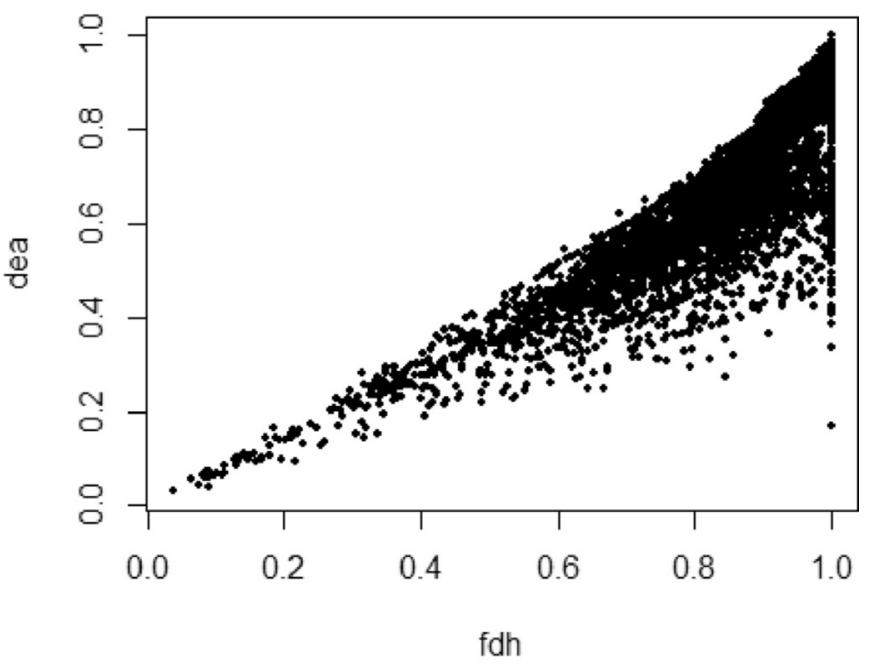

FDH vs DEA estimates in mathematics

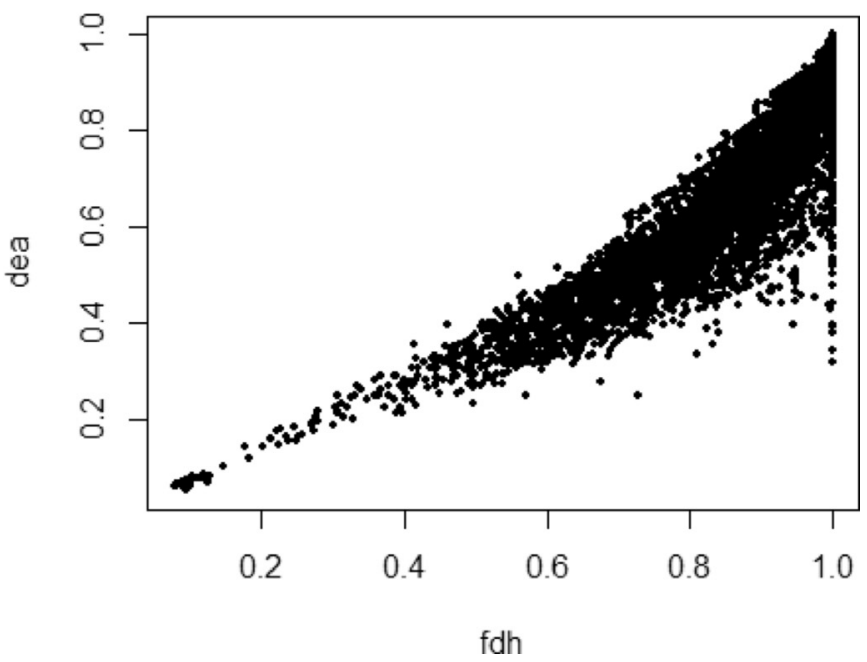

Fig. 4. FDH vs DEA efficiency scores in reading and mathematics. 
Appendix 3

Table 10

Variables of the database, collected by the questionnaires to school principals.

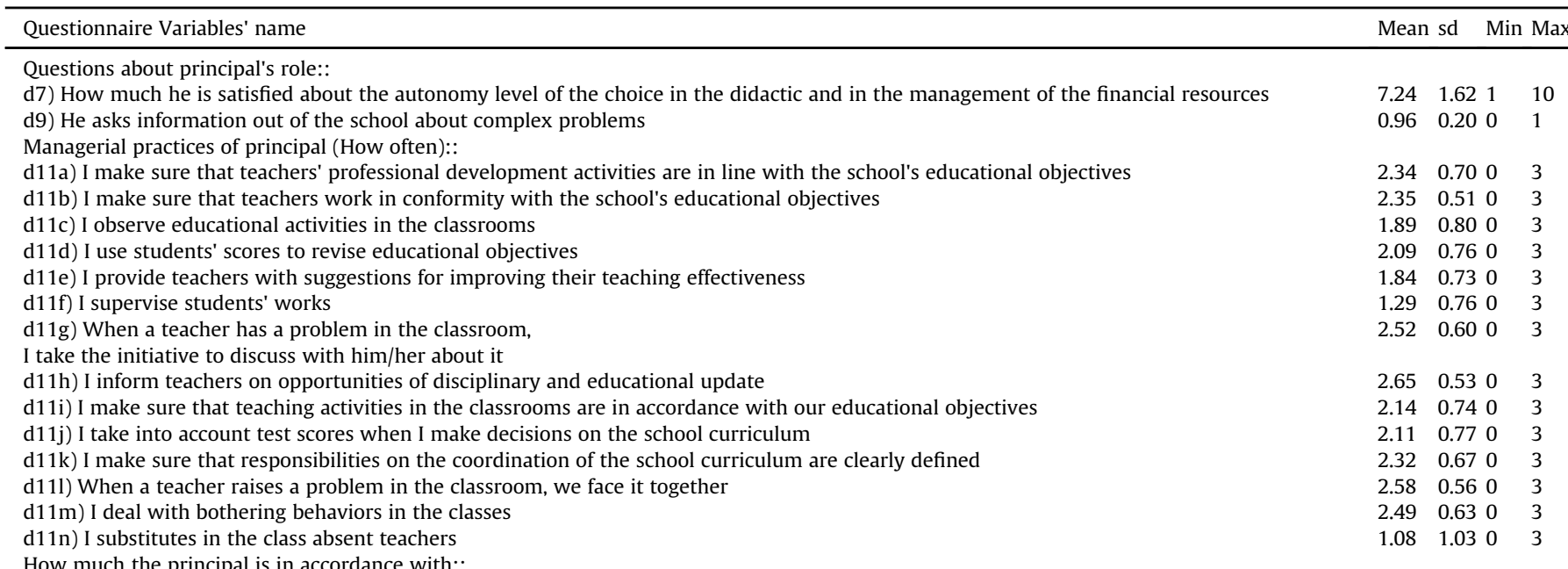

d12a) In my job, it is important to make sure that educational strategies, approved by the Ministry, are explained to new teachers and applied by $2.14 \quad 0.520 \quad 3$

more experienced teachers.

d12d) In my job, It is important to make sure that teachers' skills are improving continuously

d12e) In my job, It is important to make sure that teachers feel responsible for the achievement of school objectives

d12f) In my job, It is important to be convincing when presenting new projects to parents

$\mathrm{d} 12 \mathrm{~g}$ ) I can influence decisions on this school that are made by upper-level administrative positions

$\mathrm{d} 12 \mathrm{~h}$ ) It is important for the school to verify that rules are respected by everybody

d12i) It is important for the school to avoid mistakes in the administrative procedures

$\mathrm{d} 12 \mathrm{j}$ ) In my job, It is important to solve timetable problems and/or lesson scheduling problems

$\mathrm{d} 12 \mathrm{k}$ ) It is important that I contribute to maintain a peaceful atmosphere in the school

$\mathrm{d} 12 \mathrm{~m}$ ) In this school, we work by objectives and/or on the basis of the formative offer plan

$\mathrm{d} 12 \mathrm{n})$ I define the objectives to be reached by the school personnel

$\mathrm{d} 12^{\circ}$ ) I promote an atmosphere of projectuality aimed at reaching specific objectives

Principal features::

Female

Age

Master or similar after degree

Scientific education

Year of experience

Year of experience in the actual school

Experience in an other district

Experience with INVALSI

d14 \& d15) Teachers, Students and Parents:

Relations between students

Relations between teachers

Relations between students and teachers

Relations between teachers and parents

Relations between teachers and ATA

Relations between teachers and principal

Teachers' competences

Teachers' dedication

Didactic innovation of teachers

Preparation level of students going out

Schools Capacity to obtain public financing

Integration between school and local firms

Capacity of school to orient students to

the right choice

Capacity of school to motivate teachers

Parents' pressure 
Table 10 (continued)

Questionnaire Variables' name

Mean sd Min Max

d16) How often school proposes to parents to::

speak about the complex performance of the school

speak about how to spend the funds of the school

speak about the situation of the school's structures

offer funds to the school

voluntary work to improve the school

speak about the definition of didactic program

voluntary work for the didactic activities

speak about INVALSI results of the school

d18) How much parents::

Participate to parents' meeting

Vote at the election of the school board

Participate at the meeting between parents

and teachers

Meet teachers to have information about

their children

Offer funds for the school

Participate at the didactic activities

Voluntarily participate at manual activities

Participate at gathering of capital for the school

Participate at associations to help the school

Questionnaire Variables' Name

d19) How much students:

Arrive late at school

Have unjustified absences

Disturb in class

Stea

Are aggressive with other students

Scare or offend other students

Are aggressive with teachers

d22 \& d23) School's Structures/Infrastructures

Gymnasium

Library

Open-air spaces

Computer lab

Linguistic lab

Scientific lab

Artistic/music lab

Technical lab

Theater lab

Heating

Didactic materials

Writing materials

Books for consulting

Book loan

Audiovisual support

Computer in the classes

Interactive multimedia board

Software used for teaching

Tablet/Notebook

Internet connection

$\begin{array}{llll}1.24 & 0.81 & 0 & 3\end{array}$

$\begin{array}{llll}1.25 & 0.81 & 0 & 3\end{array}$

$\begin{array}{llll}1.53 & 0.82 & 0 & 3\end{array}$

$\begin{array}{llll}1.21 & 0.87 & 0 & 3\end{array}$

$\begin{array}{llll}1.48 & 0.79 & 0 & 3\end{array}$

$\begin{array}{llll}0.50 & 0.66 & 0 & 3\end{array}$

$\begin{array}{llll}1.16 & 0.74 & 0 & 3\end{array}$

$\begin{array}{llll}0.96 & 0.83 & 0 & 3\end{array}$

$\begin{array}{llll}2.12 & 0.61 & 0 & 3\end{array}$

$\begin{array}{llll}1.86 & 0.63 & 0 & 3\end{array}$

$\begin{array}{llll}2.36 & 0.550 & 0\end{array}$

$2.51 \quad 0.520 \quad 3$

$\begin{array}{llll}1.32 & 0.88 & 0 & 3\end{array}$

$\begin{array}{llll}1.46 & 0.72 & 0 & 3\end{array}$

$\begin{array}{llll}1.17 & 0.93 & 0 & 3\end{array}$

$\begin{array}{llll}1.38 & 0.88 & 0 & 3\end{array}$

$\begin{array}{llll}1.19 & 0.960 & 0\end{array}$

Mean sd Min Max

$\begin{array}{llll}1.11 & 0.52 & 0 & 3\end{array}$

$\begin{array}{lllll}0.67 & 0.56 & 0 & 3\end{array}$

$\begin{array}{lllll}1.29 & 0.57 & 0 & 3\end{array}$

$\begin{array}{llll}0.28 & 0.46 & 0 & 3\end{array}$

$\begin{array}{llll}0.71 & 0.55 & 0 & 3\end{array}$

$\begin{array}{lllll}0.54 & 0.57 & 0 & 3\end{array}$

$\begin{array}{llll}0.47 & 0.560 & 0\end{array}$

$\begin{array}{llll}1.82 & 0.51 & 0 & 2\end{array}$

$\begin{array}{llll}1.40 & 0.71 & 0 & 2\end{array}$

$\begin{array}{llll}1.61 & 0.65 & 0 & 2\end{array}$

$\begin{array}{llll}1.81 & 0.440 & 0\end{array}$

$\begin{array}{lllll}0.82 & 0.94 & 0 & 2\end{array}$

$\begin{array}{lllll}1.35 & 0.80 & 0 & 2\end{array}$

$\begin{array}{llll}1.58 & 0.72 & 0\end{array}$

$\begin{array}{llll}0.62 & 0.87 & 0 & 2\end{array}$

$\begin{array}{llll}0.59 & 0.85 & 0 & 2\end{array}$

$\begin{array}{llll}1.93 & 1.27 & 0 & 2\end{array}$

$\begin{array}{llll}1.88 & 0.33 & 0 & 2\end{array}$

$\begin{array}{llll}1.82 & 0.39 & 0 & 2\end{array}$

$\begin{array}{llll}1.52 & 0.58 & 0 & 2\end{array}$

$\begin{array}{llll}1.40 & 0.72 & 0 & 2\end{array}$

$\begin{array}{llll}1.55 & 0.53 & 0 & 2\end{array}$

$\begin{array}{llll}1.64 & 0.48 & 0 & 2\end{array}$

$\begin{array}{llll}1.53 & 0.52 & 0 & 2\end{array}$

$\begin{array}{lllll}1.40 & 0.57 & 0 & 2\end{array}$

$\begin{array}{lllll}0.93 & 0.78 & 0 & 2\end{array}$

$\begin{array}{lllll}1.57 & 0.54 & 0 & 2\end{array}$ 


\section{Appendix 4}

\begin{tabular}{|c|c|}
\hline Areas of management & Questions \\
\hline \multirow{7}{*}{ Operations } & D11j. I take into account test scores when I make decisions on the school curriculum. \\
\hline & $\begin{array}{l}\text { D12a. In my job, it is important to make sure that educational strategies, approved by the Ministry, are } \\
\text { explained to new teachers and applied by more experienced teachers. }\end{array}$ \\
\hline & D12i. It is important for the school to avoid mistakes in administrative procedures. \\
\hline & D12j. In my job, It is important to solve timetable problems and/or lesson scheduling problems. \\
\hline & D12m. In this school, we work by objectives and/or on the basis of the formative offer plan. \\
\hline & D12n. I define the objectives to be reached by the school personnel. \\
\hline & D120. I promote an atmosphere of projectuality aimed at reaching specific objectives. \\
\hline \multirow{4}{*}{ Monitoring } & D11c. I observe educational activities in the classrooms. \\
\hline & D11f. I supervise students' works. \\
\hline & D11m. I deal with bothering behaviors in the classes. \\
\hline & D12h. It is important for the school to verify that rules are respected by everybody. \\
\hline \multirow{4}{*}{ Targets } & $\begin{array}{l}\text { D11a. I make sure that teachers' professional development activities are in line with the school's educational } \\
\text { objectives. }\end{array}$ \\
\hline & D11b. I make sure that teachers work in conformity with the school's educational objectives. \\
\hline & D11d. I use students' scores to revise educational objectives. \\
\hline & $\begin{array}{l}\text { D11i. I make sure that teaching activities in the classrooms are in accordance with our educational } \\
\text { objectives. }\end{array}$ \\
\hline \multirow{5}{*}{ People } & D11e. I provide teachers with suggestions for improving their teaching effectiveness. \\
\hline & D11g. When a teacher has a problem in the classroom, I take the initiative to discuss with him/her about it. \\
\hline & D11h. I inform teachers on opportunities of disciplinary and educational update. \\
\hline & D11. When a teacher raises a problem in the classroom, we face it together. \\
\hline & D12d. In my job, It is important to make sure that teachers' skills are improving continuously. \\
\hline \multirow{5}{*}{ Leadership } & D11k. I make sure that responsibilities on the coordination of the school curriculum are clearly defined. \\
\hline & $\begin{array}{l}\text { D12e. In my job, It is important to make sure that teachers feel responsible for the achievement of school } \\
\text { objectives. }\end{array}$ \\
\hline & D12f. In my job, It is important to be convincing when presenting new projects to parents. \\
\hline & D12g. I can influence decisions on this school that are made by upper-level administrative positions. \\
\hline & D12k. It is important that I contribute to maintain a peaceful atmosphere in the school. \\
\hline
\end{tabular}

Fig. 5. Classification of the managerial practices in five areas. 


\section{References}

[1] Agasisti T, Bonomi F, Sibiano P. Do the managerial characteristics of schools influence their performance? Int J Educ Manag 2012;26(6):593-609.

[2] Agasisti T, Bonomi F, Sibiano P. Measuring the "managerial" efficiency of public schools: a case study in Italy. Int J Educ Manag 2014a;28(2):120-40.

[3] Agasisti T, Falzetti P, Soncin M. Italian school principals' managerial behaviors and their effect on students' test scores: an empirical analysis. In: Presented at the european group for public administration (EGPA), conference 2015; 2015.

[4] Agasisti T, Ieva F, Paganoni AM. Heterogeneity, school-effects and achievement gaps across Italian regions: further evidence from statistical modeling. 2014. MOX-report n. 07/2014.

[5] Agasisti T, Vittadini G. Regional economic disparities as determinants of students' achievement in Italy. Res Appl Econ 2012;4(2):p33-54.

[6] Andrews M, Duncombe W, Yinger J. Revisiting economies of size in American education: are we any closer to a consensus? Econ Educ Rev 2002;21(3): 245-62.

[7] Banker RD, Cooper WW, Seiford LM, Zhu J. Returns to scale in dea. In: Handbook on data envelopment analysis. Springer; 2011. p. 41-70.

[10] Berg S. Water utility benchmarking: measurement, methodologies, and performance incentives. Iwa Publishing; 2010.

[11] Blanden J, Machin S. Educational inequality and the expansion of UK higher education. Scott J Political Econ 2004;51(2):230-49.

[12] Bloom N, Lemos R, Sadun R, Van Reenen J. Does management matter in schools? Econ J 2015;125(584):647-74.

[13] Bogetoft P, Otto L. Benchmarking with dea and sfa [Computer software manual]. 2014 (R package version 0.24).

[14] Branch GF, Hanushek EA, Rivkin SG. Estimating the effect of leaders on public sector productivity: the case of school principals. National Bureau of Economic Research; 2012. report n. w17803.

[15] Bratti M, Checchi D, Filippin A. Geographical differences in italian students mathematical competencies: evidence from PISA 2003. G degli Econ Ann Econ 2007:299-333.

[16] Canty A, Ripley B. boot: bootstrap r (s-plus) functions [Computer software manual]. 2015. R package version 1.3-15.

[17] Charnes A, Cooper WW, Rhodes E. Measuring the efficiency of decision making units. Eur J Operational Res 1978;2(6):429-44.

[18] Clark D, Martorell P, Rockoff J. School principals and school performance. working paper 38. National Center for Analysis of longitudinal data in Education research; 2009.

[19] Coelli M, Green DA. Leadership effects: school principals and student outcomes. Econ Educ Rev 2012:31(1):92-109.

[20] Coelli TJ, Prasada Rao D, O'Donnell CJ, Battese GE. An introduction to efficiency and productivity analysis. Data Envel Anal 2005:161-81.

[21] Cotton K. Affective and social benefits of small-scale schooling. Eric digest. 1996.

[22] Croissant Y, Zeileis A. truncreg: truncated gaussian regression models [Computer software manual]. Retrieved from. 2013 (R package version $0.2-1$ ) http://CRAN.R-project.org/package=truncreg.

[23] De Witte K, López-Torres L. Efficiency in education: a review of literature and a way forward. J Operat Res Soc 2015. http://dx.doi.org/10.1057/jors.2015.92.

[24] De Witte K, Rogge N. Accounting for exogenous influences in performance evaluations of teachers. Econ Educ Rev 2011:30(4):641-53.

[25] Dhuey E, Smith J. How important are school principals in the production of student achievement? Can J Economics/Revue Can d'économique 2014;47(2): 634-63.

[26] Di Liberto A, Schivardi F, Sulis G. Managerial practices and student performance. Econ Policy 2015;30(84):683-728.

[27] Driscoll D, Halcoussis D, Svorny S. School district size and student performance. Econ Educ Rev 2003:22(2):193-201.

[28] Dronkers J, Robert P. Differences in Scholastic achievement of public, private government-dependent, and private independent schools a cross-national analysis. Educ Policy 2008;22(4):541-77.

[29] Eagly AH, Karau SJ, Johnson BT. Gender and leadership style among school principals: a meta-analysis. Educ Adm Q 1992;28(1):76-102.

[30] Farrell MJ. The measurement of productive efficiency. J R Stat Soc Ser A General 1957:253-90.

[31] Hall G, Rutherford WL, Hord SM, Huling LL. Effects of three principal styles on school improvement. Educ Leadersh 1984;41(5):22-9.

[32] Hallinger P. Instructional leadership and the school principal: a passing fancy that refuses to fade away. Leadersh Policy Sch 2005;4(3):221-39.

[33] Hanushek EA, Woessmann L. The economics of international differences in educational achievement. 2010. Writing paper n. w15949.

[34] Hattie J. Visible learning: a synthesis of over 800 meta-analyses relating to achievement. Routledge; 2013.

[35] Heinesen E. School district size and student educational attainment: evidence from Denmark. Econ Educ Rev 2005;24(6):677-89.

[36] Istituto nazionale per la valutazione del sistema educativo di istruzione e di formazione (invalsi). (n.d.). Retrieved from \{http://www.invalsi.it/\}.

[37] Jacobs R, Goddard M. How do performance indicators add up? An examination of composite indicators in public services. Public Money Manag 2007; 27(2):103-10.

[38] Jacobson SL, Day C, Leithwood K, Leithwood K. Understanding successful principal leadership: progress on a broken front. J Educ Adm 2005;43(6): 619-29.

[39] Krueger AB. Economic considerations and class size. Econ J 2003;113(485): F34-63.

[40] Land D. Local school boards under review: their role and effectiveness in relation to students' academic achievement. Rev Educ Res 2002;72(2): 229-78.

[41] Leithwood K, Jantzi D. A review of empirical evidence about school size effects: a policy perspective. Rev Educ Res 2009;79(1):464-90.

[42] Luyten H, Hendriks M, Scheerens J. School size effects revisited: a qualitative and quantitative review of the research evidence in primary and secondary education. Springer; 2014.

[43] Marks HM, Printy SM. Principal leadership and school performance: an integration of transformational and instructional leadership. Educ Adm Q 2003;39(3):370-97.

[44] Masci C, Ieva F, Agasisti T, Paganoni AM. Does class matter more than school? Evidence from a multilevel statistical analysis on Italian junior secondary school students. Socio-Economic Plan Sci 2016a;54:47-57.

[45] Masci C, leva F, Agasisti T, Paganoni AM. Bivariate multilevel models for the analysis of mathematics and reading pupils' achievements. J. Appl. Stat. 2016. http://dx.doi.org/10.1080/02664763.2016.1201799.

[46] Meier KJ, O'Toole LJ. Public management and educational performance: the impact of managerial networking. Public Adm Rev 2003;63(6):689-99.

[47] Melyn W, Moesen W. Towards a synthetic indicator of macroeconomic performance: unequal weighting when limited information is available, public economics research paper 17. KU Leuven: Center for Economic Studies; 1991.

[48] Mohrman Susan Albers. School-Based Management: Organizing for High Performance. Jossey-Bass Inc. Publishers; 1994. San Francisco, CA 94104.

[49] Newman M, Garrett Z, Elbourne D, Bradley S, Noden P, Taylor J, et al. Does secondary school size make a difference?: A systematic review. Educ Res Rev 2006;1(1):41-60.

[50] Perry L, McConney A. Does the SES of the school matter? An examination of socioeconomic status and student achievement using PISA 2003. The Teachers College Record 2010;112(4):7-8.

[51] Programme for International Student Assessment (PISA). (n.d.). Retrieved from \{http://www.oecd.org/pisa/\}.

[52] R Core Team. R: a language and environment for statistical computing [computer software manual]. 2014. Vienna, Austria, http://www.R-project. org/.

[53] Robertson FW. Economies of scale for large school districts: a national study with local implications. Soc Sci J 2007;44(4):620-9.

[54] Robertson PJ, Wohlstetter P, Mohrman SA. Generating curriculum and instructional innovations through school-based management. Educ Adm Q 1995;31(3):375-404.

[56] Sarrico CS, Lee Rhodes M, Halligan J, Sarrico CS, Rosa MJ, Manatos MJ. School performance management practices and school achievement. Int J Prod Perform Manag 2012;61(3):272-89.

[57] Simar L, Wilson PW. Sensitivity analysis of efficiency scores: how to bootstrap in nonparametric frontier models. Manag Sci 1998;44(1):49-61.

[58] Simar L, Wilson PW. A general methodology for bootstrapping in nonparametric frontier models. J Appl Statistics 2000;27(6):779-802.

[59] Simar L, Wilson PW. Estimation and inference in two-stage, semi-parametric models of production processes. J Econ 2007;136(1):31-64.

[60] Sleegers P, Bergen T, Giesbers J. The policy-making capacity of schools results of a Dutch study. Educ Manag Adm Leadersh 1994;22(3):147-59.

[62] Thanassoulis E, Da Conceicao M, Silva Portela A. School outcomes: sharing the responsibility between pupil and school1. Educ Econ 2002;10(2):183-207. 